\title{
DOWN PAYMENT POLICY AND ECONOMIC FLUCTUATIONS IN A HETEROGENEOUS DSGE MODEL: THE CASE OF CHINA
}

\author{
Yiyao HE \\ School of Economics, Zhejiang University, Zheda Road no. 38, Hangzhou, China
}

Received 05 June 2018; accepted 27 January 2019

\begin{abstract}
Motivated by the observation that the down payment policy in China is government-controlled and pro-cyclical based on the housing market, I construct a heterogeneous DSGE model to study the relationship between Chinas down payment policy, property tax, and economic fluctuations. The results indicate that an increasing down payment ratio suppresses the speculative belief and decreases household's housing demand. This in turn pulls housing prices down and smoothes the economic fluctuations. By way of counterfactual exercises, I also find that the down payment policy and the property tax can be substitutes for each other. If there is an active down payment policy, the implementation of property tax shall be prudently deliberated by the Chinese government.
\end{abstract}

Keywords: heterogeneous beliefs, down payment policy, economic fluctuations, property tax, DSGE, social welfare.

\section{Introduction}

The 2008 financial crisis in the U.S. has led to an increasing number of studies on the potential link between the housing market and the real economy. Chinese housing prices have increased rapidly in recent decades (Chen \& Wen, 2017). Recognizing the potential importance of the housing market to the economy, this paper studies the link between them in China. However, instead of emphasizing the channel of using housing as collateral, I focus on the Chinese down payment policy, which is a crucial macro policy targeted in the housing market. According to the data from the National Bureau of Statistics, it has a strong relationship with the real economy.

In China, the down payment policy is governmentcontrolled $^{1}$ and pro-cyclical based on the housing market. The related documents about down payment ratio issued by the central government since 2003 are presented in Table 1 . The average and legal minimum down payment ratios from 2003:Q3 to 2016:Q2 are concluded in Table 2. It is clear that the down payment policy has been frequently used. During the 13 years from 2003 to 2016, 13 documents have been issued by the central government. And

\footnotetext{
1 From 2003 to 2016, the Std. Dev. of the down payment ratio in the U.S., U.K, and China are 5.56, 1.23 and 9.17 respectively. The government-controlled down payment policy in China has larger fluctuations than those of other countries.
}

the down payment policy has been used more and more frequently. Since September 2014, the down payment ratio has been adjusted four times. As China currently has no property tax, the down payment policy can be recognized as one of the most effective and important tools by which the Chinese government targets the housing market.

Furthermore, as shown in Figure 1, the down payment ratio has a significant effect on the real economy. ${ }^{2}$ The solid line indicates the tight down payment policy with increasing down payment ratio, while the dash line denotes the loose down payment policy with the decreasing down payment ratio (i.e., from 2014 to 2016, the down payment ratio continues to decline in Table 2). It is clear that after the down payment policy is loosened, there is always an obvious increase in GDP growth. After the down payment policy is tightened, the GDP growth rate declines. Combining with Table 2, it seems that the down payment policy influences the GDP growth rate cycles by responding pro-cyclically to the economic cycles of housing market. ${ }^{3}$

2 Since two of the documents in Table 1 only point out policy orientation without precise down payment adjustment, so there are only 11 changes in Figure 1.

3 Based on the Statistical Yearbook of China, the Chinese housing market is important as it makes a contribution to GDP growth rate by more than $11.96 \%$.

${ }^{*}$ Corresponding author. E-mail: heyiyao@zju.edu.cn 


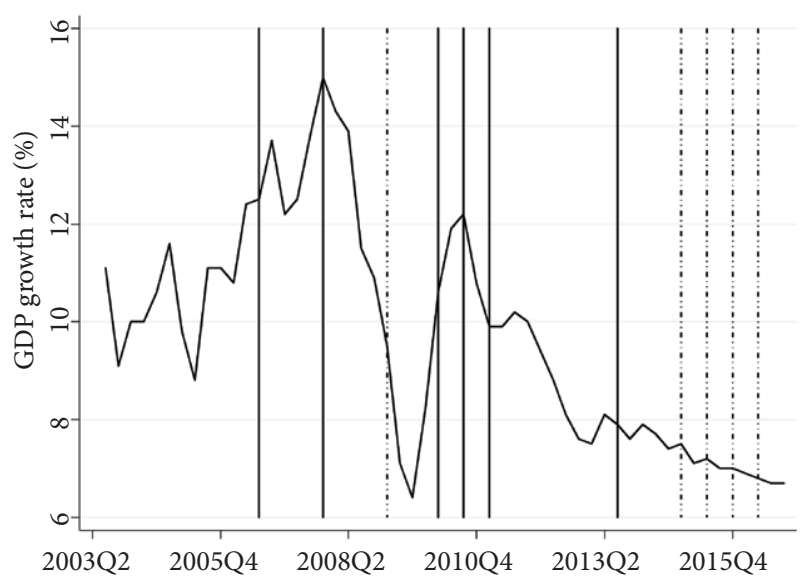

Figure 1. GDP growth rate and the down payment policy

This paper examines the down payment policy's effects on China's economic fluctuations in a heterogeneous DSGE model. Cutler, Poterba, and Summers (1990), Barberis, Greenwood, Jin, and Shleifer $(2015,2018)$ introduce "feedback traders" whose demand is based on the history of past returns rather than the expectation of future fundamentals. Brock and Hommes (1998) also investigates the dynamics of asset price with heterogeneous beliefs to explain the price fluctuations. Since housing serves both as a consumer good and an investment product, I wish to extend a standard DSGE model to incorporate heterogeneous beliefs based on behavioural economics, which lays a micro foundation for a standard DSGE model.

I also examine the important influence of the down payment policy on the housing market and the real economy fluctuations by a quantitative general equilibrium work. This kind of work is related to a growing strand of literature (Glaeser, Gyourko, \& Saks, 2005; Davis \& Heathcote, 2007; Fisher, 2007; Iacoviello, 2005; Iacoviello \& Neri, 2010; Favilukis, Ludvigson, \& Van Nieuwerburgh, 2017). Although it is widely accepted that the government's down payment policy could have an important influence on housing prices and macroeconomic fluctuations, quantitative studies in a general equilibrium framework have been scant. This paper aims to fill part of this gap by modelling in a quantitative general equilibrium framework.

The rest of the paper is organized as follows. Section 1 presents the model, section 2 highlights the basic mechanism under calibration by quantitative analysis and the last section concludes.

Table 1. Down payment policy documents (data source: The People's Bank of China and the State Council)

\begin{tabular}{|c|l|}
\hline Time & \multicolumn{1}{|c|}{ Document name } \\
\hline 2003.6 & Notice on further strengthening the management of real estate credit business \\
\hline 2005.3 & Notice on the adjustments of commercial bank housing credit policy and the excess reserve deposit interest rate \\
\hline 2006.5 & Notice on adjusting the housing credit policy \\
\hline 2007.9 & Notice on strengthening the management of commercial real estate credit \\
\hline 2008.12 & Opinions on promoting the healthy development of the real estate market \\
\hline 2009.12 & Four regulations from the State Council (Guo si tiao in Chinese) \\
\hline 2010.4 & Notice from the State Council on curbing the excessive rise in housing prices in some cities \\
\hline 2011.1 & Notice from the State Council on further improving the regulation and control of the real estate market \\
\hline 2013.2 & New five regulations from the State Council (Guo wu tiao in Chinese) \\
\hline 2014.9 & Notice on further improving housing financial services \\
\hline 2015.3 & Notice on personal housing loan policy issues \\
\hline 2015.9 & Notice on further improving the differentiated housing credit policy \\
\hline 2016.2 & Notice on the adjustment of individual housing loan policy \\
\hline 2016.10 & Some local governments increase down payment ratios ${ }^{4}$ \\
\hline
\end{tabular}

Table 2. Down payment ratio (national level, \%) (data source: The People's Bank of China and the State Council ${ }^{5}$ )

\begin{tabular}{|c|c|c|c|c|c|c|c|c|}
\hline \multirow{2}{*}{ Quarters } & \multicolumn{4}{|c|}{ Average down payment ratio } & \multirow[t]{2}{*}{ Trend } & \multirow{2}{*}{$\begin{array}{l}\text { The year-on-year } \\
\text { growth rate of housing } \\
\text { market investment }\end{array}$} & \multicolumn{2}{|c|}{$\begin{array}{l}\text { The legal } \\
\text { minimum down } \\
\text { payment }\end{array}$} \\
\hline & $\begin{array}{l}1^{\text {st }} \text { suite } \\
\left(>90 \mathrm{~m}^{2}\right)\end{array}$ & $\begin{array}{c}1^{\text {st }} \text { suite } \\
\left(<=90 \mathrm{~m}^{2}\right)\end{array}$ & $\begin{array}{l}2^{\text {nd }} \text { suite } \\
\text { (no loan) }\end{array}$ & $\begin{array}{l}2^{\text {nd }} \text { suite } \\
\text { (with loan) }\end{array}$ & & & $1^{\text {st }}$ suite & $2^{\text {nd }}$ suite \\
\hline 2003Q3-2008Q3 & 24.44 & 20.00 & 31.90 & 31.90 & Tight & 28.31 & 20 & 30 \\
\hline 2008Q4-2009Q4 & 20.67 & 20.00 & 21.33 & 21.33 & Loose & 12.35 & 20 & 20 \\
\hline 2010Q1-2014Q3 & 29.30 & 27.72 & 57.98 & 57.98 & Tight & 25.10 & 30 & 50 \\
\hline 2014Q4-2016Q2 & 26.67 & 26.67 & 30.00 & 44.76 & Loose & 6.00 & 20 & 30 \\
\hline
\end{tabular}

4 Chinese housing market is unusually heated in 2016. Although the central government has not yet issued documents, the down payment ratio of $1^{\text {st }}$ suite has already been raised to 35\% in Beijing and Shanghai in October 2016. Therefore, the down payment policy is not only the most frequently used by the Chinese government to regulate the housing market, but also the policy that is most easily thought of.

5 Government often issues a document in the middle of a quarter, which leads to a non-integer average down payment ratio. 


\section{Model}

The model makes two extensions to a standard DSGE model. First, following Liu, Wang, and Zha (2013), I assume that household holds housing and that housing is used as an input in the production of the consumption good. Second the heterogeneous beliefs in the representative household sector are introduced.

\subsection{The representative household}

The household has the utility function

$$
E \sum_{t=0}^{\infty} \beta^{t}\left[\ln C_{t}+\varphi \ln H_{t}-\psi \frac{N_{t}^{1+\eta}}{1+\eta}\right],
$$

where: $\varphi$ and $\psi>0$, parameter $\beta \in(0,1)$ is a subjective discount factor; $C_{t}$ denotes consumption; $H_{t}$ denotes housing holding and $N_{t}$ denotes labor hour. Denote by $w_{t}$ the real wage, by $\theta_{t}$ the exogenous down payment ratio and by $P_{t}$ the housing price. The budget constraint for the household is given by

$$
\begin{aligned}
& C_{t}+\theta_{t} P_{t} H_{t}+\left(1-\theta_{t}\right) P_{t} H_{t}+\left(1+r_{t-1}\right) L_{t-1}= \\
& L_{t}+w_{t} N_{t}+P_{t} H_{t-1},
\end{aligned}
$$

where: the external borrowing, $L_{t}=\left(1-\theta_{t}\right) P_{t} H_{t}$, equals to the non-down payment part of housing purchase. Specifically, the down payment policy rule follows the stochastic process

$$
\ln \theta_{t}=\rho_{\theta} \ln \theta_{t-1}+\varepsilon_{\theta t} .
$$

The parameter $\rho_{\theta} \in(-1,1)$, and $\varepsilon_{\theta t}$ is i.i.d. standard normal processes.

The household chooses $\left\{C_{t}, H_{t}, N_{t}\right\}$ to maximize (1) subject to (2)-(3). So the first order condition of $H_{t}$ is

$$
\underbrace{\theta_{t} P_{t}}_{\text {marginal cost }}=\underbrace{\frac{\varphi C_{t}}{H_{t}}}_{\text {MRS }}+\underbrace{E_{t} \beta \frac{C_{t}}{C_{t+1}}\left[P_{t+1}-\left(1+r_{t}\right)\left(1-\theta_{t}\right) P_{t}\right]}_{\text {marginal expected revenue }} \text {. }
$$

If there is no down payment, $\theta_{t}=1$. The equation is reduced to $P_{t}=\frac{\varphi C_{t}}{H_{t}}+E_{t} \beta \frac{C_{t}}{C_{t+1}} P_{t+1}$. It is clear that the left hand side is the marginal cost to buy one unit housing today, which equals to the expected revenue tomorrow plus the marginal substitution rate (MRS) of consumption and housing at the right hand side. Therefore, with a non-zero down payment ratio, the marginal cost to buy one unit housing today becomes $\theta_{t} P_{t}$, the expected revenue is $E_{t} \beta \frac{C_{t}}{C_{t+1}}\left[P_{t+1}-\left(1+r_{t}\right)\left(1-\theta_{t}\right) P_{t}\right]$, and the MRS remains the same.

Here I want to introduce the heterogeneous beliefs which are commonly used in the behavioural finance. According to Cutler et al. (1990), I introduce an expectation rule for household's expectation $E_{t}(\cdot)$ and suppose that the house holding decision $H_{t}$ is affected by two heterogeneous beliefs, fundamental belief $H_{f t}$ and speculative belief $H_{s t}$. They are given by

$$
H_{f t}=\gamma\left(\bar{P}-P_{t}\right) \text {, }
$$

$$
H_{s t}=\sigma\left(P_{t}-P_{t-1}\right),
$$

where: $\gamma$ and $\sigma>0, \bar{P}$ denotes the fundamental value of house. Equation (5) and (6) imply that housing has the utility of living and acts as an asset as well. Increasing housing price on the one hand decreases fundamental belief $H_{f t}$, on the other hand stimulates speculative belief $H_{s t}$. It is worth noting that both $H_{f t}$ and $H_{s t}$ are flow variables. Therefore, I refer to Barberis et al. (2018)'s expectation rule form

$\underbrace{E_{t} \beta \frac{C_{t}}{C_{t+1}}\left[P_{t+1}-\left(1+r_{t}\right)\left(1-\theta_{t}\right) P_{t}\right]-\beta \frac{C_{t-1}}{C_{t}}\left[P_{t}-\left(1+r_{t-1}\right)\left(1-\theta_{t-1}\right) P_{t-1}\right]}_{\text {The gap of expectated revenue in two periods }}=$ $\underbrace{m H_{f t}+(1-m) H_{s t}}_{\text {flow variable }}$,

and substitute the rule back into equation (4) which yields $\theta_{t} P_{t}=\frac{\varphi C_{t}}{H_{t}}+m H_{f t}+(1-m) H_{s t}+\beta \frac{C_{t-1}}{C_{t}}\left[P_{t}-\left(1+r_{t-1}\right)\left(1-\theta_{t-1}\right) P_{t-1}\right]$, where: the parameter $m$ is the weight (fraction) of fundamental belief and the left $(1-m)$ is the weight of speculative belief. Hence, these two heterogeneous beliefs influence the optimal decision of $H_{t}$. As the DSGE model is a general equilibrium system, the $H_{t}$ will further affect the output.

\subsection{The representative entrepreneur}

Following Liu et al. (2013), the entrepreneur has the utility function

$$
E \sum_{t=0}^{\infty} \beta^{t} \ln \left(C_{e t}\right),
$$

where: $C_{e t}$ denotes the entrepreneur's consumption. The production function is given by

$$
Y_{t}=\left[H_{e, t-1}^{\phi} K_{t-1}^{1-\phi}\right]^{\alpha} N_{e t}^{1-\alpha},
$$

where: $Y_{t}, H_{e, t-1}, K_{t-1}$ and $N_{e t}$ denote output, housing holding of entrepreneur, capital and labor respectively, and parameters $\alpha$ and $\phi \in(0,1)$ measure the output elasticity of these production factors. The entrepreneur is endowed with $K_{-1}>0$ units of initial capital stock and $H_{e, t-1}>0$ units of initial housing holding. Denote $I_{t}$ and $S_{t}$ are investment and saving respectively, the entrepreneur faces the capital accumulation and budget constraint

$$
\begin{gathered}
K_{t}=(1-\delta) K_{t-1}+I_{t}, \\
C_{e t}+P_{t}\left(H_{e t}-H_{e, t-1}\right)+S_{t}=Y_{t}-I_{t}+S_{t-1}\left(1+r_{t-1}\right)-w_{t} N_{e t} .
\end{gathered}
$$

The entrepreneur chooses $\left\{C_{e t}, H_{e t}, S_{t}, K_{t}, N_{e t}\right\}$ to maximize (7) subject to (8)-(10).

\subsection{Market clearing conditions and equilibrium}

In a competitive equilibrium, the markets for goods, labor, housing and borrowing all clear. The goods market clearing condition implies that

$$
C_{t}+C_{e t}+I_{t}=Y_{t} .
$$


The labor market clearing condition implies that labor demand equals labor supply

$$
N_{t}=N_{e t} \text {. }
$$

The housing market clearing condition implies that

$$
H_{t}+H_{e t}=\bar{H}=1 \text {. }
$$

The financial market clearing condition implies that

$$
S_{t}=L_{t} \text {. }
$$

A competitive equilibrium consists of sequences of prices $\left\{P_{t}, w_{t}, r_{t}\right\}$ and allocations $\left\{C_{t}, C_{e t}, H_{t}\right.$, $\left.H_{f t}, H_{s t}, H_{e t}, N_{t}, I_{t}, Y_{t}, K_{t}, S_{t}\right\}_{t=0}^{\infty}$, such that (i) taking the prices as given, the allocations solve the optimizing problems for the household and the entrepreneur and (ii) all markets clear.

\section{Results}

Calibration of the model proceeds as follows. First, I loglinearized the model around the steady state. Second, I fit the log-linearized model to four quarterly China time series: the real price of housing holding, real per capita consumption, real per capita GDP, and number of employees. ${ }^{6}$ The sampled period ranges from 1999:Q1 to 2015:Q4. Data on China's macroeconomy are taken from the WIND Database, the Ministry of Land \& Resources and the China Statistical Yearbook.

Table 3 summarizes the calibrated parameter values. First, I directly calibrate the set of $\{\alpha, \beta, \eta, \delta, \phi\}$, whose numbers are commonly used in the literature of China's economy. According to Chang, Liu, Spiegel, and Zhang (2018), I set capital share $\alpha=0.5$, subjective discount factor $\beta=0.996$, inverse Frisch elasticity $\eta=2$ which implies a Frisch elasticity of labor supply of 0.5 and depreciation rate $\delta=0.025$. Output elasticity of house holdings $\phi$ is calibrated to 0.3 based on Guo, Liu, and Zhao (2015). Second, because of data availability, I calculate the average down payment ratio only starts from 2003:Q1, and the $\theta$ is set to 0.3. Barberis et al. (2018) argue that the fraction of fundamental-value traders is about $30 \%$ in the U.S. stock market. As far as I know, there is no available Chinese micro-data to estimate and separate fundamental and speculative traders or beliefs, so I set $\mathrm{m}$ to 0.3 based on Barberis et al. (2018). I will change $m$ and do robustness checks in the simulation section. Third, to match the model to the fluctuations observed in the data, I follow the approach in Sims and Zha (1998), in which the authors propose a Bayesian method to estimate the model parameters. Moreover, I refer to Liu et al. (2013) and Iacoviello (2015) for the prior distributions. Table 4 reports the estimates of structural parameters at the posterior mode. I also report the $90 \%$ probability intervals for model parameters in the table. One can see from Table 4 that the estimated shock is persistent and has large standard devia-

6 The data of working hours are not available in China, so I choose numbers of employees to measure the labor input. tion. And by targeting the quarterly time data series, both the two beliefs parameters are more precise.

Table 3. Calibrated parameters

\begin{tabular}{|c|c|l|}
\hline Parameter & Value & \multicolumn{1}{|c|}{ Description } \\
\hline$\alpha$ & 0.500 & Share of capital \\
\hline$\beta$ & 0.996 & Subjective discount factor \\
\hline$\eta$ & 2.000 & Inverse Frisch elasticity \\
\hline$\delta$ & 0.025 & Depreciation rate \\
\hline$\phi$ & 0.300 & Output elasticity of house holdings \\
\hline$\theta$ & 0.300 & Down payment ratio \\
\hline$m$ & 0.300 & $\begin{array}{l}\text { The weight (fraction) of } \\
\text { fundamental belief }\end{array}$ \\
\hline
\end{tabular}

Table 4. Parameter estimations

\begin{tabular}{|c|l|l|l|c|c|}
\hline $\begin{array}{c}\text { Para- } \\
\text { meter }\end{array}$ & Distribution & Prior & $\begin{array}{c}\text { Std. } \\
\text { Dev. }\end{array}$ & $\begin{array}{c}\text { Poste- } \\
\text { rior }\end{array}$ & $\begin{array}{c}90 \% \text { Probabil- } \\
\text { ity interval }\end{array}$ \\
\hline$\gamma$ & InvGamma & 0.25 & 0.50 & 0.2149 & {$[0.0650,0.3528]$} \\
\hline$\sigma$ & InvGamma & 0.20 & 0.50 & 0.1362 & {$[0.0500,0.2245]$} \\
\hline$\rho_{\theta}$ & Beta & 0.50 & 0.20 & 0.9278 & {$[0.8798,0.9802]$} \\
\hline$\varepsilon_{\theta t}$ & InvGamma & 0.01 & inf & 0.0213 & {$[0.0184,0.0243]$} \\
\hline
\end{tabular}

The Bayesian method includes data information, but it mostly depends on the prior disctributions (Liu et al., 2013). To check the robustness of the calibration, I alternatively estimate the $\rho_{\theta}$ and $\varepsilon_{\theta t}$ by the VAR model by using the same data in Table 2 and Figure 1:

$$
\ln \theta_{t, i}=\rho_{\theta, i} \ln \theta_{t-1, i}+\varepsilon_{\theta t, i},
$$

where: $i \in[1,2,3,4] ; 1 / 2 / 3 / 4$ denote the cases " 1 st suite (> $\left.90 \mathrm{~m}^{2}\right)^{\prime}$; "1 st $^{\text {st }}$ suite $\left(<=90 \mathrm{~m}^{2}\right)$ "; " $2^{\text {nd }}$ suite (no loan)"; " $2^{\text {nd }}$ suite (with loan)" respectively. As $i=2$ is the most common case which affects the majority citizens, I calibrate the average $\rho_{\theta}=(0.9278+0.9583) / 2$ and $\varepsilon_{\theta t, i}=$ $(0.0213+0.0408) / 2$ to do the following quantitative exercises. The results are shown in Table 5.

Table 5. Parameters of the shock

\begin{tabular}{|c|c|c|c|c|}
\hline & Coef. & Std. Err. & t value & P value \\
\hline$\rho_{\theta, 1}$ & 0.9067 & 0.0602 & 15.05 & 0.000 \\
\hline$\rho_{\theta, 2}$ & 0.9583 & 0.0408 & 23.46 & 0.000 \\
\hline$\rho_{\theta, 3}$ & 0.8900 & 0.0651 & 13.67 & 0.000 \\
\hline$\rho_{\theta, 4}$ & 0.9161 & 0.0573 & 15.99 & 0.000 \\
\hline & Std. Dev. & \multicolumn{2}{|c|}{ Min } & Max \\
\hline$\varepsilon_{\theta t, 1}$ & 0.0794 & -0.2375 & 0.2639 \\
\hline$\varepsilon_{\theta t, 2}$ & 0.0554 & -0.1719 & 0.2813 \\
\hline$\varepsilon_{\theta t, 3}$ & 0.1661 & -0.7136 & 0.6231 \\
\hline$\varepsilon_{\theta t, 4}$ & 0.1661 & -0.7136 & 0.6231 \\
\hline
\end{tabular}

As shown in Figure 2, an increase in the down payment raises the household's first payment (the left hand side of equation (4)), and lowers the expected housing resale price and revenue (the right hand side of equation (4)). 

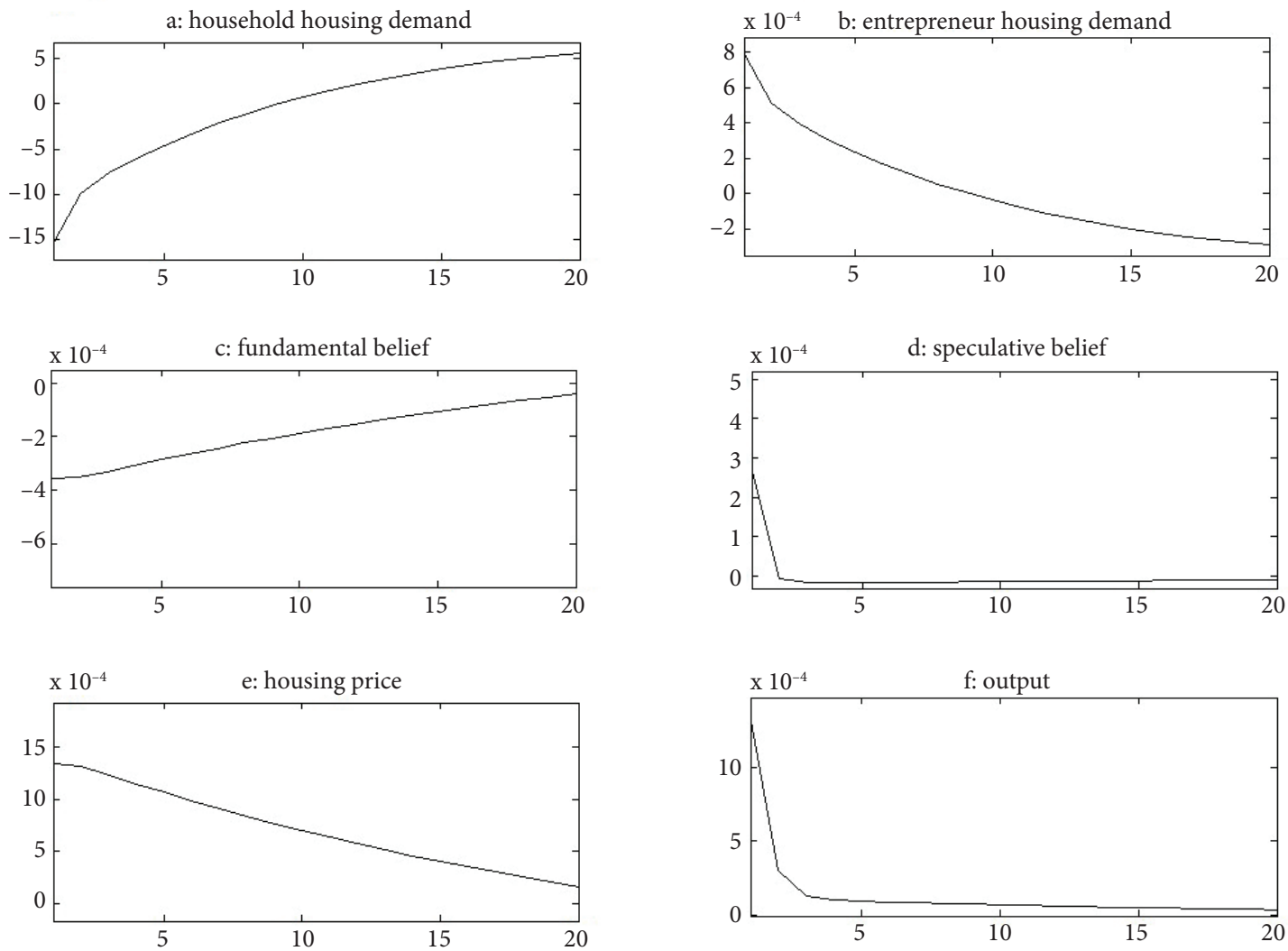

Figure 2. Impulse responses to an (one standard deviation) positive down payment shock

Therefore, increasing down payment decreases the household's housing demand (panel a). As the housing supply is fixed in the model, entrepreneur's housing demand increases (panel b). In detail, the tightened down payment policy suppresses speculative belief as it declines rapidly in panel $\mathrm{d}$ and drives fundamental belief to increase slowly in the long run at the same time (panel c).

In panel $\mathrm{e}$, entrepreneur's rising housing demand pushes the housing prices up and the prosperity of the housing market promotes a positive output impulse response (panel f). However, the increasing down payment pulls housing prices down quickly. As a result, the output has decreased and comes to the steady state rapidly. Figure 2 shows that the down payment policy is efficient to regulate housing market cyclically in China, which further smoothes the real economy.

What might happen if the Chinese government carries out a property tax for purpose of macro-control of the housing market has recently become a hot topic. In Table 6, I show that the down payment policy and property tax can be substitutes for each other.

Following Chang, Liu, and Spiegel (2015), I first compute the welfare under the benchmark policy regime (denoted by $V_{b}$ ) and under an alternative regime (denoted by $V_{a}$ ) upon obtaining the Ramsey allocations. Welfare gains are then calculated as the percentage decrease in consumption in perpetuity under the each regime such that the representative agent is indifferent between living under each regime. In terms of the model variables, the welfare gains are measured by $\Delta$ such that

$$
E \sum_{t=0}^{\infty} \beta^{t}\left[\ln C_{t}^{\operatorname{tax}}(1-\Delta)+\varphi \ln H_{t}^{\operatorname{tax}}-\psi \frac{N_{t}^{1+\eta_{\operatorname{tax}}}}{1+\eta}\right]=V_{b} \text {, }
$$

where: the variables with a superscript tax denote allocations with property tax. With log-utility in consumption, the explicit expression for welfare gains satisfies $\ln (1-\Delta)=1 /(1-\beta)\left(V_{b}-V_{a}\right)$.

Referring to the property tax rates in U.S., the tax rate $\tau_{h}$ is set to $0.015^{7}$. Compared with the benchmark model, the left hand side of equation (2) has an additional part, $\tau_{h} P_{t} H_{t}$, to represent property tax expenditures. The heterogeneous beliefs $\tilde{H}_{f t}$ and $\tilde{H}_{s t}$ satisfy

$$
\begin{aligned}
& \tilde{H}_{f t}=\gamma\left(\bar{P}-P_{t}\right) /\left(1+\tau_{h}\right), \\
& \tilde{H}_{s t}=\sigma\left(P_{t}-P_{t-1}\right) /\left(1+\tau_{h}\right) .
\end{aligned}
$$

To keep the resource constraint balanced, there is an additional government spending $G_{t}=\tau_{h} P_{t} H_{t}$.

7 The property tax rates in each state of U.S. are different. The rate in New Jersey is relatively high, reaching $1.89 \%$. However, the rate in Louisiana only accounts for $0.18 \%$. Most of the rates range from $1 \%$ to $2 \%$. Thus, the median is calibrated. 
Table 6. Macroeconomic stability and welfare under alternative policy regimes

\begin{tabular}{|c|c|c|c|}
\hline & Only down payment & Only property tax & $\begin{array}{l}\text { Down payment \& } \\
\text { property tax }\end{array}$ \\
\hline Std. Dev. of investment & 0.3770 & 0.1029 & 0.1064 \\
\hline Std. Dev. of consumption & 0.1654 & 0.1929 & 0.6312 \\
\hline Std. Dev. of output & 0.0354 & 0.0463 & 0.1325 \\
\hline Std. Dev. of labor & 0.0657 & 0.0327 & 0.2519 \\
\hline Welfare gains & - & $0.0016 \approx 0$ & -0.4521 \\
\hline \multicolumn{4}{|c|}{ Housing price changes $(\mathrm{m}=0.3)$} \\
\hline Average annual decline rate & $12.17 \%$ & $15.18 \%$ & $24.62 \%$ \\
\hline The $1^{\text {st }}$ year decline rate & $18.17 \%$ & $17.39 \%$ & $39.69 \%$ \\
\hline \multicolumn{4}{|c|}{ Robustness check: housing price changes $(\mathrm{m}=0.4)$} \\
\hline Average annual decline rate & $12.26 \%$ & $15.13 \%$ & $23.59 \%$ \\
\hline The $1^{\text {st }}$ year decline rate & $18.20 \%$ & $17.34 \%$ & $40.03 \%$ \\
\hline \multicolumn{4}{|c|}{ Robustness check: housing price changes $(\mathrm{m}=0.2)$} \\
\hline Average annual decline rate & $12.09 \%$ & $15.23 \%$ & $25.67 \%$ \\
\hline The $1^{\text {st }}$ year decline rate & $18.17 \%$ & $17.45 \%$ & $39.38 \%$ \\
\hline \multicolumn{4}{|c|}{ Robustness check: housing price changes $(\mathrm{m}=0.1)$} \\
\hline Average annual decline rate & $12.01 \%$ & $15.29 \%$ & $26.76 \%$ \\
\hline The $1^{\text {st }}$ year decline rate & $18.15 \%$ & $17.50 \%$ & $39.11 \%$ \\
\hline
\end{tabular}

Note: I follow Chang et al. (2015)'s method, and compute the welfare gains at the first-order approximations, for more details please see their footnote 9. The annual decline rate is computed from the $1^{\text {st }}$ quarter to the $20^{\text {th }}$ quarter (the same with impulse response).

Table 6 shows that the social welfare remains almost regardless of whether the down payment policy or property tax is issued. However, social welfare decreases 0.4521 with an additional property tax policy and endogenous variables fluctuate considerably. If the government implements the down payment policy and the property tax at the same time, the household's budget constraint will be tighten and consumption is crowded out excessively, thus welfare decreases.

Furthermore when I set $\mathrm{m}=0.3$, the simulation result shows that the housing price decreases at the average annual decline rate $12.17 \%$ with an increasing down payment ratio at the beginning. Specially, housing price decreases faster at the first year, then policy effect is gradually weakening. This result is in line with Figure 2. It is worthy noting that the decreasing rates are quite mild. ${ }^{8}$ Decreasing housing price will increase household's consumption and social welfare. However, with both the down payment policy and the property tax, housing price decreases too fast to stabilize the economy which leads to welfare loss in turn.

This indicates that the down payment policy and the property tax can be substitutes for each other in both short term and long term, and the effect is stronger in the short term. Because in a DSGE model, one period equals to one quarter and 20 quarters is five years. In the long run, all the macro-fluctuations will go to the steady-states

\footnotetext{
8 According to National Bureau of Economic Research, it will be identified as a crisis warning when macro-fluctuations drop more than $1 / 3$.
}

as shown in Figure 2, so the policy effect is stronger in the short term than in the long run if other conditions remain unchanged. Therefore, if there is an active down payment policy, the implementation of property tax shall be prudently deliberated by the Chinese government.

Then I change m's value to do a series of robustness checks. According to the CHFS survey by Southwest University of Finance and Economics in China, the vacancy rate of housing in China's urban areas is $21.4 \%$ in 2017 (higher than $20 \%$ of the international warning line). And this unusual high vacancy rate implies that the speculators have become the main body of Chinese housing buyers. Meanwhile, facing the continue increasing housing price, the fundamental-value buyers will be more greatly affected by the speculative belief than ever. So the speculative belief should be the primary belief, and I choose $0<\mathrm{m}<$ 0.5 to ensure that the fundamental belief retreats to the second. All the results are robust in Table 6.

\section{Conclusions}

Motivated by the observation that the down payment policy in China is government-controlled and pro-cyclical based on the housing market, I construct a heterogeneous DSGE model to study the relationship between China's down payment policy, property tax, and economic fluctuations. In the model, I assume that housing is used as an input in the production of the consumption good. The heterogeneous beliefs in the representative household sector are introduced. This paper finds that an increasing down payment ratio suppresses the speculative belief 
and decreases household's housing demand. This in turn pulls housing prices down and smoothes the economic fluctuations. By way of counterfactual exercises, I find that the social welfare remains almost the same when either the down payment policy or property tax is issued, while social welfare decreases with an additional property tax policy. Furthermore, the housing price decreases faster in the short term than in the long term with an increasing down payment ratio at the beginning.

This paper suggests that first, the down payment policy is an effective tool to regulate housing market and output. An increasing down payment ratio will decrease housing price in both short term and long term. In detail, it causes an average annual mild decline rate $12.17 \%$ and an $1^{\text {st }}$ year decline rate $18.17 \%$ which is a litter higher than the average. Second, the down payment policy and the property tax can be substitutes for each other in both short term and long term, but the substitution effect is gradually weakening in the long term. Therefore, the down payment policy and the property tax have almost the same effect on the housing market and economic fluctuations. They can be treated as interchangeable under these circumstances. If there is an active down payment policy, the implementation of property tax shall be prudently deliberated by the Chinese government.

\section{Acknowledgements}

The author thanks the anonymous reviewers for the valuable suggestions. This work is supported by the Fundamental Research Funds for the Central Universities Funding and the China Postdoctoral Science Foundation (2018M630650).

\section{Disclosure statement}

There are no conflicts of interest.

\section{References}

Barberis, N., Greenwood, R., Jin, L., \& Shleifer, A. (2018). Extrapolation and bubbles. Journal of Financial Economics, 129(2), 203-227. https://doi.org/10.1016/j.jfineco.2018.04.007

Barberis, N., Greenwood, R., Jin, L., \& Shleifer, A. (2015). XCAPM: an extrapolative capital asset pricing model. Journal of Financial Economics, 115(1), 1-24. https://doi.org/10.1016/j.jfineco.2014.08.007

Brock, W. A., \& Hommes, C. H. (1998). Heterogeneous beliefs and routes to chaos in a simple asset pricing model. Journal of Economic Dynamics and Control, 22(8), 1235-1274.
https://doi.org/10.1016/S0165-1889(98)00011-6

Chang, C., Liu, Z., \& Spiegel, M. M. (2015). Capital controls and optimal Chinese monetary policy. Journal of Monetary Economics, 74, 1-15.

https://doi.org/10.1016/j.jmoneco.2015.04.003

Chang, C., Liu, Z., Spiegel, M. M., \& Zhang, J. (2018). Reserve requirements and optimal Chinese stabilization policy. Journal of Monetary Economics (in press).

https://doi.org/10.1016/j.jmoneco.2018.08.005

Chen, K., \& Wen, Y. (2017). The great housing boom of China. American Economic Journal: Macroeconomics, 9(2), 73-114. https://doi.org/10.1257/mac.20140234

Cutler, D., Poterba, J., \& Summers, L. (1990). Speculative dynamics and the role of feedback traders. The American Economic Review, 80(2), 63-68. Retrieved from http://www.jstor.org/ stable/2006544

Davis, M. A., \& Heathcote, J. (2007). The price and quantity of residential land in the United States. Journal of Monetary Economics, 54(8), 2595-2620. https://doi.org/10.1016/j.jmoneco.2007.06.023

Favilukis, J., Ludvigson, S. C., \& Van Nieuwerburgh, S. (2016). The macroeconomic effects of housing wealth, housing finance, and limited risk sharing in general equilibrium. Journal of Political Economy, 125(1), 140-223. https://doi.org/10.1086/689606

Fisher, J. D. M. (2007). Why does household investment lead business investment over the business cycle? Journal of Political Economy, 115(1), 141-168. https://doi.org/10.1086/511994

Glaeser, E. L., Gyourko, J., \& Saks, R. E. (2005). Why have housing prices gone up? American Economic Review, 95(2), 329333. https://doi.org/10.1257/000282805774669961

Guo, S., Liu, L., \& Zhao, Y. (2015). The business cycle implications of land financing in China. Economic Modelling, 46, 225-237. https://doi.org/10.1016/j.econmod.2014.12.033

Iacoviello, M. (2005). House prices, borrowing constraints, and monetary policy in the business cycle. American Economic Review, 95(3), 739-764. https://doi.org/10.1257/0002828054201477

Iacoviello, M. (2015). Financial business cycles. Review of Economic Dynamics, 18(1), 140-163. https://doi.org/10.1016/j.red.2014.09.003

Iacoviello, M., \& Neri, S. (2010). Housing market spillovers: evidence from an estimated DSGE model. American Economic Journal: Macroeconomics, 2(2), 125-164. https://doi.org/10.1257/mac.2.2.125

Liu, Z., Wang, P., \& Zha, T. (2013). Land-price dynamics and macroeconomic fluctuations. Econometrica, 81(3), 1147-1184. https://doi.org/10.3982/ECTA8994

Sims, C., \& Zha, T. (1998). Bayesian methods for dynamic multivariate models. International Economic Review, 39(4), 949968. https://doi.org/doi:10.2307/2527347 